DOI: $10.15593 / 2224-9982 / 2018.53 .07$

УДК 665.612 .2

А.А. Шилова, Н.Ю. Бачева

Пермский национальный исследовательский политехнический университет, Пермь, Россия

\author{
ОПРЕДЕЛЕНИЕ КОЭФФИЦИЕНТОВ ИЗБЫТКА ВОЗДУХА \\ НА ВЕРХНЕМ И НИЖНЕМ ПРЕДЕЛАХ ГОРЕНИЯ \\ ЗАБАЛЛАСТИРОВАННЫХ НЕФТЯНЫХ ГАЗОВ
}

\begin{abstract}
В последние годы особую актуальность приобрел вопрос утилизации нефтяных газов. На малодебитных месторождениях целесообразно применение утилизационных микротурбинных установок с выработкой электрической энергии. Для разработки универсальной камеры сгорания такой энергоустановки требуются расчетные и экспериментальные исследования характеристик горения реальных нефтяных газов. Нефтяные газы различных месторождения имеют сугубо различный состав и теплопрозводительность, причем содержание негорючих компонентов в них может достигать $90 \%$. В связи с этим очень важно изучение концентрационных пределов горения реальных забалластированных нефтяных газов. В данной работе расчетным путем определены объемные доли горючего и коэффрициент избытка воздуха на верхнем и нижнем концентрационных пределах горения реальных нефтяных газов. В результате исследования сделан вывод о том, что в утилизационных камерах сгорания целесообразно работать вблизи верхнего концентрационного предела при коэффрициентах избытка воздуха больше трех. Однако, область устойчивого горения нефтяных газов определяется не только концентрационными пределами, но и отношением скоростей газовоздушной смеси и горения. При горении забалластированных нефтяных газов вблизи верхней концентрационной границы область устойчивого горения сильно сужается при реальных условиях подачи.

Ключевые слова: забалластированный нефтяной газ, концентрационные пределы горения, скорость газовоздушной смеси, коэфффициент избытка воздуха.
\end{abstract}

\author{
A.A. Shilova, N.Yu. Bacheva
}

Perm National Research Polytechnic University, Perm, Russian Federation

\title{
DETERMINATION OF THE EXCESS AIR COEFFICIENTS AT THE UPPER AND LOWER COMBUSTION LIMITS OF BALLASTED OIL GASES
}

In recent years, the issue of utilization of oil gases has become especially topical. At low-yield deposits, it is advisable to use recycling microturbine plants with the generation of electric energy. To develop a universal combustion chamber of such an energy installation, calculation and experimental studies of the combustion characteristics of real oil gases are required. Oil gases of different deposits have a very different composition and thermal conductivity, and the content of non-combustible components in them can reach up to $90 \%$. In connection with this, it is very important to study the concentration limits of combustion of real ballasted oil gases. In this paper, the volumetric fractions of the fuel and the excess air coefficient at the upper and lower concentration limits of the combustion of real oil gases were calculated by calculation. As a result of the study, it was concluded that it is expedient to work in the utilization chambers near the upper concentration limit with excess air coefficients exceeding three. However, the region of stable combustion of oil gases is determined not only by concentration limits, but also by the ratio of the rates of the gas-air mixture and combustion. In the combustion of ballasted petroleum gases near the upper concentration boundary, the region of stable combustion strongly narrows under real conditions of delivery.

Keywords: ballast oil gas, concentration limits of combustion, gas-air mixture rate, air excess ratio.

\section{Введение}

Перед нефтедобывающими предприятиями в последнее время остро стоит вопрос утилизации нефтяных газов. Ежегодно в России извлекается от 30 до 60 млрд м углеводородного сырья и лишь 11-12 млрд м ${ }^{3}$ поступает на газоперерабатывающие заводы [1]. Создание высокоресурсной малоэмиссионной камеры сгорания является весьма важным вопросом при разработке газотурбинных установок для утилизации нефтяных газов (НГ) на малодебитных месторождениях [2-4]. На разных малодебитных месторождениях нефтяной газ сильно отличается по 
составу и теплопроизводительности. Для создания универсальной камеры сгорания (КС), которая обеспечивала бы устойчивое горение разнородных по составу нефтяных газов разных месторождений, необходимо знать области устойчивого горения по коэффициенту избытка воздуха $[5,6]$. В данной работе определены коэффициенты избытка воздуха на верхнем и нижнем пределах горения отдельных горючих газов и реальных нефтяных газов в широком диапазоне содержания балластирующих компонентов.

\section{Математическая модель}

Нижний или верхний пределы воспламенения НГ без балластирующих компонентов в объемных процентах [7]

$$
L=\frac{r_{1}+r_{2}+\ldots+r_{n}}{\frac{r_{1}}{L_{1}}+\frac{r_{2}}{L_{2}}+\ldots+\frac{r_{n}}{L_{n}}},
$$

где $r_{1}, r_{2}, \ldots, r_{n}$ - содержание горючих компонентов в НГ, об. \%; $L_{1}, L_{2}, \ldots, L_{n}-$ верхние или нижние пределы воспламенения горючих компонентов, об. \%.

Нижний или верхний предел воспламенения НГ с балластирующими компонентами рассчитываются по разным методикам [8].

Нижний концентрационный предел в объемных процентах рассчитывается по формуле

$$
L_{\mathrm{H}}=\frac{100}{1+v_{\mathrm{B}}},
$$

где $v_{\text {в }}$ - количество молей воздуха, приходящегося на 1 моль исходной смеси.

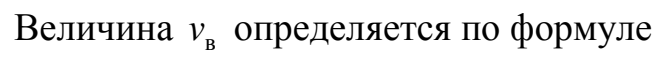

$$
v_{\mathrm{B}}=\sum \frac{r_{j}^{\text {гор }}}{L_{\mathrm{r} j}^{\text {гор }}}-\frac{\sum r_{j}^{\text {гор }}+\sum r_{\mathrm{K}}^{\text {бал }} \cdot c_{\mathrm{\kappa}}}{100},
$$

где $r_{j}^{\text {гор }}-$ концентрация $j$-го горючего компонента в НГ, об. \%; $L_{\text {н } j}^{\text {го }}-$ нижний предел горения

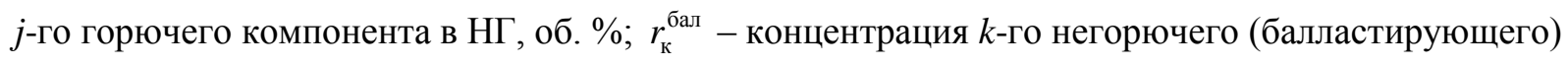
компонента в НГ, об. \%; $c_{\mathrm{\kappa}}-$ коэффициент $k$-го негорючего компонента.

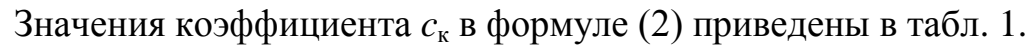

Таблица 1

Значения коэффициента $c_{\mathrm{k}}$ в формуле (2) для негорючих компонентов смеси

\begin{tabular}{|c|l|c|c|}
\hline$k$ & \multicolumn{1}{|c|}{ Негорючий компонент } & Формула вещества & $c_{\mathrm{K}}$ \\
\hline 1 & Азот & $\mathrm{N}_{2}$ & 0,988 \\
\hline 2 & Двуокись углерода & $\mathrm{CO}_{2}$ & 1,590 \\
\hline 3 & Водяной пар & $\mathrm{H}_{2} \mathrm{O}$ & 1,247 \\
\hline
\end{tabular}

Верхний предел распространения пламени для НГ с содержанием негорючих компонентов рассчитывается так:

$$
L_{\mathrm{B}}=\frac{\sum r_{j}^{\text {гор }}+\sum r_{\mathrm{\kappa}}^{\text {бал }}}{\sum r_{j}^{\text {гор }} / L_{\mathrm{B} j}^{\text {гор }}+\sum r_{k}^{\text {гор }} / L_{\mathrm{B} k}^{\text {бал }}},
$$

где $L_{\mathrm{B} j}^{\text {гор }}-$ верхний предел горения $j$-го горючего компонента, об. \%; $L_{\mathrm{B} k}^{\text {бал }}-$ условный верхний предел горения $k$-го негорючего компонента, об. \%. 
Условный верхний предел горения $L_{\mathrm{B} k}^{\text {бал }}$ в объемных процентах рассчитывается по формуле

$$
L_{\mathrm{B} k}^{\text {бал }}=\frac{L_{\phi k}}{\left[1-\frac{\sum r_{j}^{\text {rop }} / L_{\mathrm{Bj}}^{\text {rop }}}{\sum r_{j}^{\text {rop }} / L_{\mathrm{H} j}^{\text {rop }}}\right]\left(1-K_{\phi}\right)},
$$

где $L_{\phi k}-$ минимальная флегматизирующая концентрация $k$-го негорючего компонента, об. \%; $K_{\phi}$ - общий коэффициент флегматизации.

Минимальные флегматизирующие концентрации негорючих компонентов $L_{\phi k}$ в объемных процентах определяются по следующим зависимостям:

$$
\begin{aligned}
L_{\mathrm{\phi N}_{2}} & =100 \frac{0,00865 \Delta H+1,256+2,528 m_{\mathrm{C}}+0,759 m_{\mathrm{H}}}{1,8+5,946 m_{\mathrm{C}}+1,486 m_{\mathrm{H}}}, \\
L_{\mathrm{\phi CO}_{2}} & =100 \frac{0,00736 \Delta H+0,584+1,292 m_{\mathrm{C}}+0,427 m_{\mathrm{H}}}{1,020+4,642 m_{\mathrm{C}}+1,160 m_{\mathrm{H}}}, \\
L_{\mathrm{\phi H}_{2} \mathrm{O}} & =100 \frac{0,00802 \Delta H+0,780+1,651 m_{\mathrm{C}}+0,527 m_{\mathrm{H}}}{1,236+5,0 m_{\mathrm{C}}+1,250 m_{\mathrm{H}}},
\end{aligned}
$$

где $\Delta H$ - стандартная теплота образования горючей части НГ, кДж/моль; $m_{\mathrm{C}}, m_{\mathrm{H}}-$ количество атомов С и Н в условной химической формуле горючей части НГ.

Стандартная теплота образования горючей части $\Delta H$ в кДж/моль

$$
\Delta H=\frac{\sum r_{j} \Delta H_{j}}{\sum r_{j}},
$$

где $\Delta H_{j}$ - стандартная теплота образования $j$-го горючего компонента в НГ, кДж/моль:

Количество атомов $m_{i} i$-го горючего элемента:

$$
m_{i}=\frac{\sum r_{j} z_{i j}}{\sum r_{j}},
$$

где $z_{i j}$ - количество атомов $i$-го элемента в $j$-м компоненте.

Общий коэффициент флегматизации:

$$
K_{\phi}=\frac{\sum K_{\phi k} r_{k}}{\sum r_{k}} .
$$

Коэффициенты флегматизации негорючих компонентов:

$$
K_{\phi k}=\frac{\sum r_{j}}{\sum r_{j} / K_{\phi j}} .
$$

Значения коэффициента $K_{\phi j}$ в формуле (4) приведены в табл. 2.

Коэффициент избытка воздуха на верхнем или нижнем пределах горения:

$$
\alpha=\frac{1}{K_{v 0}} \frac{100-L}{L},
$$

где $L$ - верхний или нижний предел горения НГ, об. \%; $K_{v 0}$ - объемное стехиометрическое соотношение между воздухом и НГ. 
Значения коэффициентов $K_{\phi j}$

\begin{tabular}{|c|l|c|c|c|}
\hline \multirow{2}{*}{$k$} & \multirow{2}{*}{ Флегматизатор } & \multicolumn{3}{|c|}{$K_{\phi j}$ при флегматизации } \\
\cline { 3 - 5 } & & Органических веществ & Молекулярного водорода & Окиси углерода \\
\hline 1 & Азот & 0,1 & 0,003 & 0,02 \\
\hline 2 & Двуокись углерода & 0,19 & 0,018 & 0,096 \\
\hline 3 & Водяной пар & 0,16 & - & - \\
\hline
\end{tabular}

Стехиометрическое объемное соотношение между воздухом и НГ:

$$
K_{v 0}=K_{m 0} \frac{\rho_{\text {гор }}}{\rho_{\text {ок }}}
$$

где $K_{m 0}-$ стехиометрическое массовое соотношение компонентов; $\rho_{\text {гор }}, \rho_{\text {ок }}-$ плотности НГ и воздуха соответственно.

Стехиометрическое массовое соотношение [9]:

$$
K_{m 0}=\frac{\frac{8}{3} g_{\mathrm{C}}^{\text {rop }}+8 g_{\mathrm{H}}^{\text {rop }}+g_{\mathrm{S}}^{\text {гор }}-g_{\mathrm{O}}^{\text {гор }}}{g_{\mathrm{O}}^{\text {ок }}-\frac{8}{3} g_{\mathrm{C}}^{\text {ок }}-8 g_{\mathrm{H}}^{\text {ок }}-g_{\mathrm{S}}^{\text {ок }}},
$$

где $g_{i}^{\text {гор }}, g_{i}^{\text {ок }}-$ массовые содержания $i$-го элемента в составе НГ и воздуха соответственно.

Массовые доли $i$-го элемента:

$$
g_{i}=\frac{A_{i} \cdot m_{i}}{\sum A_{i} \cdot m_{i}}
$$

где $A_{i}$ - атомная масса $i$-го элемента; $m_{i}$ - количество атомов $i$-го элемента в условной химической формуле воздуха или НГ.

\section{Анализ полученных результатов}

Нефтяные газы различных месторождений сильно отличаются друг от друга по составу и по теплопроизводительности. Состав НГ отличается от состава природного газа большим количеством этана, пропана, бутана и других предельных углеводородов. НГ включает в себя не только газовую, но и парообразные продукты, высокомолекулярные конденсаты (пентаны, гексаны и т.д.), а также вещества, которые не являются углеводородами - меркаптаны, сероводород, азот, двуокись углерода, гелий.

Условно НГ можно разделить на несколько групп в зависимости от содержания углеводородов: чистый, содержащий 95-100 \% углеводородов; углеводородный с примесью углекислого газа от 4 до $20 \%$; углеводородный с примесью азота от 3 до $15 \%$; углеводородноазотный, в котором азот составляет больше $15 \%$ [10].

В табл. 3 приведены верхний $L_{\mathrm{B}}$ и нижний $L_{\mathrm{H}}$ концентрационные пределы горючих компонентов, которые могут входить в состав НГ.

Здесь же приведены расчетные массовые $K_{m 0}$ и объемные $K_{v 0}$ стехиометрические соотношения для каждого горючего компонента в паре с воздухом. Коэффициенты избытка воздуха на верхнем $\alpha_{\text {в }}$ и нижнем $\alpha_{\text {н }}$ концентрационных пределах получены с использованием формулы (5).

Анализ данных табл. 1 показывает, что для горючих газов по отдельности и горючих смесей можно организовывать как богатое $(\alpha<1)$, так и бедное $(\alpha>1)$ горение. Стехиометрическое соотношение $\alpha=1$ всегда попадает в диапазон устойчивого горения. 
Пределы горения горючих газов и смесей

\begin{tabular}{|l|c|c|c|c|c|c|}
\hline & $L_{\mathrm{B}}$, об. \% & $L_{\mathrm{H}}$, об. \% & $K_{m 0}$ & $K_{\text {v0 }}$ & $\alpha_{\mathrm{B}}$ & $\alpha_{\mathrm{H}}$ \\
\hline $\mathrm{H}_{2} \mathrm{~S}$ & 45 & 4,5 & 6,1 & 7,278 & 0,168 & 2,919 \\
\hline $\mathrm{C}_{6} \mathrm{H}_{14}$ & 8 & 1 & 15,27 & 45,515 & 0,253 & 2,175 \\
\hline $\mathrm{C}_{5} \mathrm{H}_{12}$ & 7,8 & 1,5 & 15,359 & 38,315 & 0,309 & 1,838 \\
\hline $\mathrm{C}_{4} \mathrm{H}_{10}$ & 8,6 & 1,8 & 15,492 & 32,460 & 0,332 & 1,681 \\
\hline $\mathrm{C}_{3} \mathrm{H}_{8}$ & 9,5 & 2,3 & 15,708 & 24,399 & 0,39 & 1,741 \\
\hline $\mathrm{C}_{2} \mathrm{H}_{6}$ & 12,5 & 3,2 & 16,127 & 16,952 & 0,413 & 1,784 \\
\hline $\mathrm{CH}_{4}$ & 15 & 5 & 17,279 & 9,604 & 0,59 & 1,978 \\
\hline $\mathrm{H}_{2}$ & 71,4 & 6,2 & 34,558 & 2,408 & 0,166 & 6,284 \\
\hline $\begin{array}{l}\mathrm{C}_{\text {месь }} \\
\left(\mathrm{CH}_{4}-91,7 \text { об.\%, } \mathrm{C}_{2} \mathrm{H}_{6}-2,5 \text { об.\%, }\right. \\
\mathrm{C}_{6} \mathrm{H}_{14}-0,4 \text { об.\%) }\end{array}$ & 14,866 & 4,846 & 16,28 & 8,909 & 0,642 & 2,204 \\
\hline
\end{tabular}

В табл. 4 приведены составы реальных НГ с различных месторождений $[6,11]$.

Таблица 4

Компонентный состав нефтяных газов

\begin{tabular}{|c|l|c|c|c|c|c|c|c|c|c|c|}
\hline \multirow{2}{*}{} & \multirow{2}{*}{ Компонент } & \multicolumn{10}{|c|}{ Нефтяные газы, об. \% } \\
\cline { 3 - 14 } & & 1 & 2 & 3 & 4 & 5 & 6 & 7 & 8 & 9 & 10 \\
\hline$j=1$ & $\mathrm{CH}_{4}$ & 72,7 & 49,2 & 39,5 & 52,5 & 58 & 28 & 18,68 & 5,1 & 8,36 & 4,18 \\
\hline$j=2$ & $\mathrm{C}_{2} \mathrm{H}_{6}$ & 3,9 & 15,8 & 20,6 & 14,7 & 7,2 & 13,2 & 15,18 & 3,1 & 5,12 & 2,04 \\
\hline$j=3$ & $\mathrm{C}_{3} \mathrm{H}_{8}$ & 8,7 & 16,8 & 20 & 10,5 & 8,5 & 17,5 & 15,92 & 5,5 & 4,23 & 2,31 \\
\hline$j=4$ & $\mathrm{C}_{4} \mathrm{H}_{10}$ & 8,9 & 9,4 & 7,6 & 7,4 & 7 & 9,8 & 7,38 & 9,8 & 1,68 & 1,45 \\
\hline$j=5$ & $\mathrm{C}_{5} \mathrm{H}_{12}$ & 4,2 & 5,6 & 3,5 & 3,7 & 5,8 & 4,8 & 1,29 & 5,2 & 1,21 & 0,65 \\
\hline$j=6$ & $\mathrm{C}_{6} \mathrm{H}_{14}$ & 0 & 0 & 0 & 0 & 0 & 0 & 0,32 & 0 & 0,39 & 0,2 \\
\hline$j=7$ & $\mathrm{H}_{2} \mathrm{~S}$ & 0 & 0 & 0,4 & 0 & 0 & 0 & 0,3 & 0 & 0 & 0 \\
\hline$k=1$ & $\mathrm{CO}_{2}$ & 0,6 & 0,7 & 3,2 & 3 & 3 & 0,5 & 0,9 & 4,7 & 0,31 & 0,03 \\
\hline$k=2$ & $\mathrm{~N}_{2}$ & 1 & 2,5 & 5,2 & 8,2 & 10,5 & 26,2 & 40,3 & 66,6 & 78,7 & 89,03 \\
\hline$k=3$ & $\mathrm{H}_{2} \mathrm{O}$ & 0 & 0 & 0 & 0 & 0 & 0 & 0 & 0 & 0 & 0 \\
\hline & $\begin{array}{l}\text { Негорючие } \\
\text { компоненты }\end{array}$ & 1,6 & 3,2 & 8,4 & 11,2 & 13,5 & 26,7 & 41,2 & 71,3 & 79,01 & 89,06 \\
\hline
\end{tabular}

В табл. 4 показаны составы НГ различных месторождений России: 1 - Мамонтовское месторождение (Ханты-Мансийский автономный округ); 2 - Усинское месторождение (Республика Коми); 3 - Уршакское месторождение (Республика Башкортостан); 4 - Зимняя Ставка (Ставропольский край); 5 - Старогрозненское месторождение (Чеченская республика); 6 - Елабужское месторождение (Республика Татарстан); 7 - Шемети (Пермский край); 8 - Салаушское месторождение (Тульская область); 9 - Гремихинское месторождение (Удмуртская Республика.); 10 - Чутырское месторождение (Удмуртская Республика).

В составе реальных НГ различных месторождений содержание негорючих компонентов может достигать 90 \%. С увеличением их содержания сужаются концентрационные пределы горения. Тяжелые углеводороды (пентан и выше) с содержанием до $10 \%$ при условиях подачи в утилизационную камеру ГТУ могут находиться в конденсированном состоянии. Попадание жидких углеводородов в КС может привести к самовозгоранию и распространению пламени 
вверх по потоку. Содержание сероводорода в составе НГ до 3 \% увеличивает концентрацию серосодержащих соединений $\mathrm{SO}_{x}$ в составе продуктов сгорания, что может привести к коррозионному уносу конструктивных элементов по «горячему» тракту.

По приведенной модели были определены нижние $L_{\mathrm{H}}$ и верхние $L_{\mathrm{B}}$ концентрационные пределы реальных НГ № 1-10 по формулам (1) и (3). Результаты расчетов в виде графических зависимостей представлены на рис. 1.

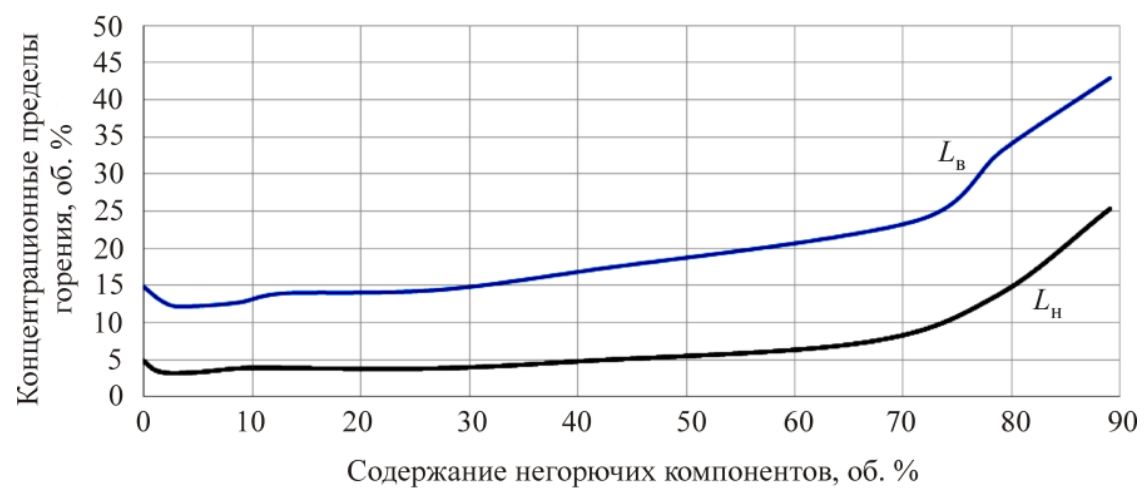

Рис. 1. Зависимости верхнего и нижнего концентрационных пределов горения НГ от содержания негорючих компонентов

В известных исследованиях $[12,13]$ рассматривались вопросы горения конкретного горючего газа с добавление различного рода флегматизаторов. В этих работах показано, что с увеличением содержания негорючих компонентов в смеси область устойчивого горения сокращается до полного прекращения горения.

Анализ данных на рис. 1 показывает, что в реальных НГ с увеличением содержания негорючих компонентов область устойчивого горения возрастает. Это, по-видимому, связано с изменением горючего потенциала горючей части реальных НГ.

На рис. 2 приведены зависимости коэффициента избытка воздуха на нижнем и верхнем пределах горения от содержания негорючих компонентов в реальных НГ.

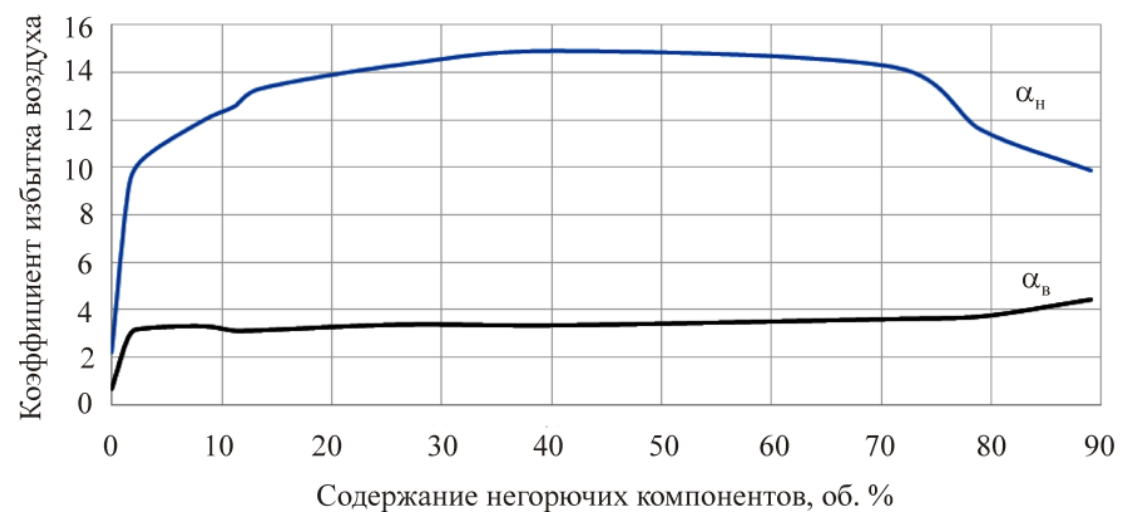

Рис. 2. Зависимости коэффициентов избытка воздуха на верхнем и нижнем пределах горения от содержания негорючих компонентов

Анализ данных, представленных на рис. 2, позволяет сделать вывод о том, что при организации сжигания разнородных, сильно забалластированных НГ разных месторождений в утилизационных КС микротурбинных установок необходимо ориентироваться на бедное горение газовоздушной смеси при $\alpha>3$. Область, примыкающая к нижнему пределу концентрационного горения $\alpha_{\text {н }}$ в таких КС не может быть реализована из-за больших габаритных размеров ком- 


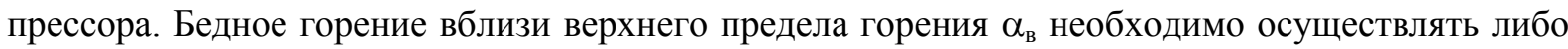
по диффузионному (раздельная подача окислителя и горючего в КС), либо по кинетическому механизму (подача в КС предварительно подготовленной газовоздушной смеси). Экспериментальные исследования [14] показывают, что КС для утилизации НГ может быть выполнена однозонной, в отличие от КС на керосине или природном газе.

Экспериментальные исследования по горению реальных НГ показали, что при соответствующем подборе расходов воздуха и НГ (коэффициента избытка воздуха $\alpha$ ) можно успешно сжигать НГ с большим содержанием балластирующих компонентов без их предварительного смешения с горючими типа керосин или природный газ. Однако при разработке КС для утилизации сильно забалластированных НГ необходимо кроме концентрационных пределов горения учитывать дополнительно газодинамические характеристики горения.

На рис. 3 показаны границы устойчивости пламени от коэффициента избытка воздуха $\alpha$ и скорости истечения топливовоздушной смеси $W_{\mathrm{TBC}}[15]$.

При организации рабочего процесса утилизационной КС ГТУ необходимо учитывать, что зона устойчивого горения забалластированного НГ сильно зависит от состава НГ и от отношения $W_{\mathrm{TBC}} / U$, где $U$ - скорость горения топливовоздушной смеси.

Положение фронта пламени считается устойчивым, если при установившемся режиме подачи топливного газа оно стабилизируется вблизи устья форсунки и не меняет своего среднего положения в пространстве.

Если $W_{\mathrm{TBC}}<U$, то возможен проскок пла-

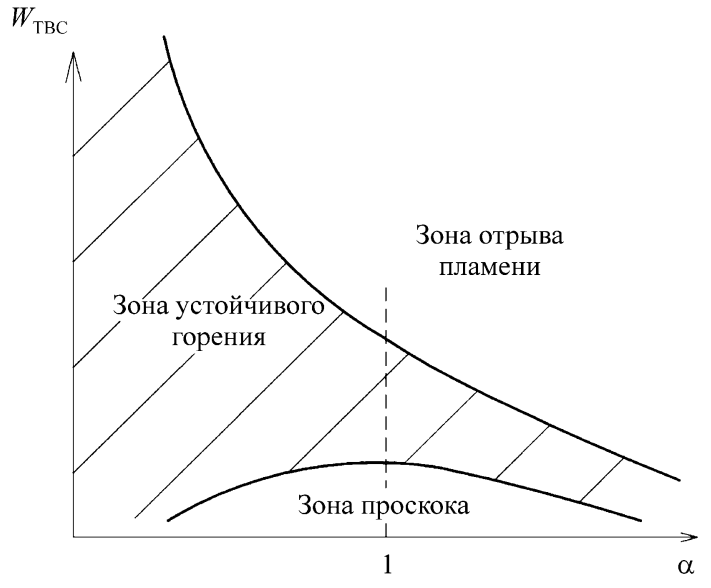

Рис. 3. Влияние газодинамических характеристик и коэффициента избытка воздуха на зону устойчивого горения забалластированных газов мени внутрь форсунки. Если $W_{\mathrm{TBC}}>U$, то свежая смесь не успевает прогреться за счет рециркуляции продуктов сгорания и происходит погасание пламени (отрыв пламени).

Как видно из рис. 3, при бедном горении (горение забалластированных, реальных НГ при $\alpha>3)$ пределы устойчивого горения сильно сокращаются. Горение топливовоздушной смеси устойчиво лишь в очень узком диапазоне изменения ее скорости. В этом случае при конструировании утилизационной КС необходимо предусмотреть повышение температурного уровня воспламенения топливовоздушной смеси, например, с помощью закручивания потоков.

Таким образом, анализ концентрационных пределов горения сильно забалластированных НГ показал, что в утилизационных КС необходимо организовывать горение в области, примыкающей к верхнему концентрационному пределу. При этом можно рассматривать варианты диффузионного или кинетического горения. В КС для утилизации НГ область устойчивого горения будет зависеть не только от концентрационных пределов, но и от газодинамических характеристик горения, которые сильно зависят от скорости подачи топливовоздушной смеси.

Статья публикуется при поддержке гранта РФФИ № 16-48-590072 «Разработка энергоустановки для утилизации нефтяных газов на малодебитных месторождениях с выработкой электрической энергии».

\section{Библиографический список}

1. Ахмадишин И.И., Запасов Р.А., Чернов И.А Оценка горючести попутного нефтяного газа с большим содержанием азота // Энергоресурсосбережение в промышленности, жилищно-коммунальном 
хозяйстве и агропромышленном комплексе: материалы регион. науч.-практ. семинара (г. Ижевск, 26 февраля - 26 апреля 2016 г.). - Ижевск: ИННОВА. - 2016. - С. 273-278.

2. Выбор геометрических, режимных и тепловых параметров высокоресурсной камеры сгорания для утилизации ПНГ / О.А. Бетинская (Зуева), Н.Л. Бачев, Р.В. Бульбович, А.М. Клещевников // Газовая промышленность. - 2013. - № 698. - С. 94-97.

3. Расчетные исследования внутрикамерного процесса при утилизации нефтяного газа / О.А. Бетинская, Н.Л. Бачев, О.О. Матюнин, Р.В. Бульбович, Н.Ю. Бачева // Нефтяное хозяйство. - 2017. - № 7. C. 86-89.

4. Разработка газотурбинной установки для утилизации нефтяного газа с выработкой электрической и тепловой энергии на малодебитных месторождениях / О.А. Бетинская (Зуева), Н.Л. Бачев, Р.В. Бульбович, А.М. Клещевников // Нефтяное хозяйство. - 2014. - № 1084. - С. 98-101.

5. Бетинская О.А. (Зуева). Концентрационные пределы горения попутных нефтяных газов // Вестник Пермского национального исследовательского политехнического университета. Аэрокосмическая техника. - 2014. - № 37. - С. 140-153.

6. Бетинская О.А. (Зуева). Пределы устойчивого горения нефтяных газов // Нефтяное хозяйство. 2014. - № 1089. - С. 64-66.

7. Померанцев В.В., Арефьев К.М., Адмедов Д.Б. Основы практической теории горения. - Л.: Энергоатомиздат. - 1986. - 312 с.

8. Сафонов С.К. Методы расчета показателей пожарной опасности газов и жидкостей; УВАУ ГА. Ульяновск, 2005. - 42 с.

9. Добровольский М.В. Жидкостные ракетные двигатели. - М.: Изд-во МГТУ им. Н.Э. Баумана, 2005. - 488 c.

10. Акинин Н.И., Бабайцев И.В., Гериш В.А. Влияние флегматизирующих газов на механизм реакций в зоне горения и температуру горения // Пожаровзрывобезопасность. - 2010. - Т. 19, № 12. C. $13-15$.

11. Геология и геохимия природных горючих газов: справочник / В.И. Ермаков, Л.М. Зорькин, В.А. Скоробогатов, В.И. Старосельский. - М.: Недра, 1990. - 315 с.

12. Сабденов К.О. Нахождение концентрационных пределов горения на основе анализа диффузионно-тепловой неустойчивости пламени. Смесь метан/воздух/разбавитель // Физика горения и взрыва. 2016. - Т. 52, № 4. - С. 24-35.

13. Процессы горения / И.М. Абдурагимов, А.С. Андросов, Л.К. Исаев, Е.В. Крылов; ВИПТШ МВД СССР. - М., 1984. - 268 с.

14. Бетинская О.А. Организация рабочего процесса в универсальной камере сгорания газотурбинной установки для утилизации попутного нефтяного газа: дис. ... канд. техн. наук: 05.04.12. - Пермь, 2017. - 146 с.

15. Белоусов В.Н., Смирнова О.С., Смородин С.Н. Основы сжигания газа: учеб. пособие; СПбГТУРП. - СПб., 2009. - 40 с.

\section{Reference}

1. Akhmadishin I.I., Zapasov R.A., Chernov I. A. Otsenka goryuchesti poputnogo neftyanogo gaza s bolshim soderzhaniyem azota [Assessment of flammability of associated petroleum gas with a high nitrogen content].Energoresursosberezheniye v promyshlennosti, zhilishchno-kommunalnom khozyaystve i agropromyshlennom komplekse: materialy regionalnogo nauchno-prakticheskogo seminara. Izhevsk: INNOVA, 2016, pp. $273-278$.

2. Betinskaya O.A. (Zuyeva O.A.), Bachev N.L., Bulbovich R.V., Kleshchevnikov A.M. Vybor geometricheskikh, rezhimnykh i teplovykh parametrov vysokoresursnoy kamery sgoraniya dlya utilizatsii PNG [The choice of geometric, regime and thermal parameters of a high-resource combustion chamber for utilization of associated petroleum gas]. Gas Industry Magazine, 2013, no. 698, pp. 94-97.

3. Betinskaya O.A., Bachev N.L., Matyunin O.O, Bul'bovich R.V., Bacheva N.YU. Raschetnyye issledovaniya vnutrikamernogo protsessa pri utilizatsii neftyanogo gaza [Calculation studies of the intra-chamber process in the utilization of petroleum gas]. Neftyanoye khozyaystvo, 2017, no. 7, pp. 86-89.

4. Betinskaya O.A. (Zueva O.A.), Bachev N.L., Bulbovich R.V., Kleshchevnikov A.M. Razrabotka gazoturbinnoy ustanovki dlya utilizatsii neftyanogo gaza s vyrabotkoy elektricheskoy i teplovoy energii na malodebitnykh mestorozhdeniyakh [Development of a gas turbine plant for utilization of associated petroleum gas for gathering electrical and thermal energy at marginal fields]. Neftyanoe khozyaystvo, 2014, no. 1084, pp. $98-101$. 
5. Betinskaya O.A. (Zuyeva O.A.). Kontsentratsionnyye predely goreniya poputnykh neftyanykh gazov [Concentration limits of combustion of associated petroleum gases]. PNRPU Aerospace Engineering Bulletin, Perm, 2014, no. 37, pp. 140-153.

6. Betinskaya O.A. Predely ustoychivogo goreniya neftyanykh gazov [Limits of sustained combustion of petroleum gases]. Neftyanoye khozyaystvo, 2014, no. 1089, pp. 64-66.

7. Pomerantsev V.V., Arefev K.M., Admedov D.B. Osnovy prakticheskoy teorii goreniya [Basics of practical combustion theory]. Leningrad: Energoatomizdat, 1986. 312 p.

8. Safonov S.K. Metody rascheta pokazateley pozharnoy opasnosti gazov i zhidkostey [Methods for calculating fire hazard indicators for gases and liquids]. Ulyanovsk: ULYANOVSKIY INSTITUT GRAZHDANSKOY AVIATSII, 2005, 42 p.

9. Dobrovolskiy M.V. Zhidkostnyye raketnyye dvigateli [Liquid rocket engines]. Moscow: Izdatelstvo MGTU im. N.E. Baumana, 2005, 488 p.

10. Akinin N.I., Babaytsev I.V., Gerish V.A. Vliyaniye flegmatiziruyushchikh gazov na mekhanizm reaktsiy $\mathrm{v}$ zone goreniya i temperaturu goreniya [Influence of phlegmatizing gases on the mechanism of reactions in the combustion zone and combustion temperature]. Fire and Explosion Safety, 2010, Vol. 19, no. 12, pp. 13-15.

11. Yermakov V.I., Zorkin L.M., Skorobogatov V.A., Starosel'skiy V.I. Geologiya i geokhimiya prirodnykh goryuchikh gazov: Spravochnik [Geology and geochemistry of natural combustible gases: Handbook]. Moscow: Nedra, 1990, 315 p.

12. Sabdenov K.O. Nakhozhdeniye kontsentratsionnykh predelov goreniya na osnove analiza diffuzionno-teplovoy neustoychivosti plameni. Smes metan/ vozdukh/razbavitel [The determination of the concentration limits of combustion on the basis of an analysis of the diffusion-thermal instability of the flame. Mixture of methane / air / diluent.]. Combustion, Explosion and Shock Waves, 2016, Vol. 52, no. 4, pp. 24-35.

13. Abduragimov I.M., Androsov A.S., Isayev L.K., Krylov Ye.V. Protsessy goreniya [Combustion processes]. Moscow: Vysshaya inzhenernaya pozharno-tekhnicheskaya shkola MVD SSSR, 1984, 268 p.

14. Betinskaya O.A. Organizatsiya rabochego protsessa v universalnoy kamere sgoraniya gazoturbinnoy ustanovki dlya utilizatsii poputnogo neftyanogo gaza [Organization of the working process in the universal combustion chamber of a gas turbine unit for utilization of associated petroleum gas. Abstract of Ph. D. thesis]. Perm, 2017, 146 p.

15. Belousov V.N., Smirnova O.S., Smorodin S.N. Osnovy szhiganiya gaza: uchebnoye posobiye [Fundamentals of gas combustion: tutorial]. St. Petersburg: Sankt-Peterburgskiy gosudarstvennyy technologicheskiy universitet rastitelnykh polimerov, 2009, $40 \mathrm{p}$.

\section{Об авторах}

Шилова Алена Алексеевна (Пермь, Россия) - студентка кафедры «Ракетно-космическая техника и энергетические системы», ФГБОУ ПНИПУ (614990, г. Пермь, Комсомольский пр., д. 29, e-mail: alyona1203@gmail.com).

Бачева Надежда Юрьевна (Пермь, Россия) - старший преподаватель кафедры «Прикладная физика», ФГБОУ ПНИПУ (614990, г. Пермь, Комсомольский пр., д. 29, e-mail: bnl54@ yandex.ru).

\section{About the authors}

Alyona A. Shilova (Perm, Russian Federation) - Student, Department of Rocket and Space Engineering and Power Generating Systems, Perm National Research Polytechnic University (29, Komsomolsky av., Perm, 614990, Russian Federation, e-mail: alyona1203@gmail.com).

Nadezhda Yu. Bacheva (Perm, Russian Federation) - Senior Lecturer, Department of Applied Physics, Perm National Research Polytechnic University (29, Komsomolsky av., Perm, 614990, Russian Federation, e-mail: bn154@yandex.ru).

Получено 14.05.2018 